\title{
An Assessment of Gasification of Lipid-Extracted Algae by Thermodynamic Simulation
}

\author{
Kazi Bayzid Kabir and Kawnish Kirtania \\ Department of Chemical Engineering, Bangladesh University of Engineering and Technology (BUET), \\ Dhaka-1000, Bangladesh
}

\begin{abstract}
Thermodynamic simulation of gasification of Nannochloropsis gaditana (after lipid extraction and before lipid extraction) over a wide range of temperatures $\left(800-1400{ }^{\circ} \mathrm{C}\right)$ was performed in this study. The reactor temperature variation with respect to the $\mathrm{O}_{2}$ to fuel ratio and the syngas composition with temperature were evaluated for gasification performance. The results showed the $\mathrm{H}_{2} / \mathrm{CO}$ ratio for lipidextracted algae (LEA) was very similar to the gasification behavior of raw algae (RA) before lipid extraction. Only a slight variation was observed for the lower heating value $\left(9.2 \mathrm{MJ} / \mathrm{Nm}^{3}\right.$ for $\mathrm{RA}$ and 8.9 $\mathrm{MJ} / \mathrm{Nm}^{3}$ for LEA at $1000{ }^{\circ} \mathrm{C}$ ) of the syngas from the two feedstocks. The $\mathrm{H}_{2} / \mathrm{CO}$ ratio for both RA and LEA remained almost the same over the range of temperatures $\left(800-1400{ }^{\circ} \mathrm{C}\right)$ under consideration. The cold gas efficiency was found between $82 \%$ to $75 \%$ for RA and $75 \%$ to $69 \%$ for LEA at $1000{ }^{\circ} \mathrm{C}$ and $1400{ }^{\circ} \mathrm{C}$ respectively. As the overall gasification performance did not degrade significantly after extraction of lipid from algae, the LEA holds remarkable potential as a gasification feedstock in a biorefinery set up.
\end{abstract}

Keywords: Gasification, Lipid-extracted algae, Thermodynamic simulation

\section{Introduction}

In the past decade, the earth has experienced a drastic rise in the surface temperature due to the greenhouse gas release, reaching more than 400 ppm of $\mathrm{CO}_{2}$ concentration in the atmosphere [1]. Other than the rising sea level, this might result in serious disasters like unbearable humidity leading to human death in near future [2,3]. To mitigate the $\mathrm{CO}_{2}$ emission from source, it is of absolute urgency to adopt a sustainable strategy to utilize the current technology infrastructure for the gradual transition from fossil fuel to renewables. The use of the available infrastructure and knowledge will result in minimal requirement for modification and cost allocation allowing the existing energy producers to switch from fossil to renewable energy sources. One such replacement for fossil fuel could be biomass which can take the advantage of utilizing state of the art technology.

Among several types of biomass, the type categorizes as third generation is considered to be the most suitable for energy production as it does not compete with food and not limited by the production rate [4]. The most promising third generation biomass is considered to be microalgae for its high production rate and lipid content making it suitable for biodiesel production [4,5]. However, the process of lipid extraction from algae and biodiesel production can incur significant cost resulting in a biodiesel price 10 times higher than the traditional fossil oil [6]. Only increasing the efficiency in extracting lipid from algae would not suffice to make it economically feasible. On the other hand, it might be possible to produce an array of products from microalgae combining several conversion methods forming a biorefinery to make the whole process economically feasible. A potential next step could be the utilization of the lipid extracted residue from algae through thermochemical pathway [7]. It was reported in several studies $[7,8]$ that more than $90 \%$ of the carbon may remain intact in the lipid extracted residue. In some cases, the percentage of carbon even increased due to the removal of oxygen during lipid extraction [8]. This remaining carbon can very well be the source of fuel and fine chemicals if an appropriate conversion method is used. One such conversion process producing energy and chemicals efficiently leaving no residual carbon is gasification.

Being a relatively mature technology for coal utilization, the possibilities with microalgae gasification had been explored by researchers for practical applications [9-11]. While gasification alone might have some prospect, it is rather costeffective to utilize the residue from a process which can already produce slightly more valuable product. However, only a few studies had tested the lipid extracted algae in laboratory scale $[7,8,12]$. This indicates the lack of data available for practical scale application to gain an in-depth understanding of large scale utilization of algae (after lipid extraction) under variable process conditions. To address this issue, this study assesses the full scale gasification plant simulation considering lipid extracted algae as feedstock comparing with pure algae gasification. The process parameters, i.e., temperature and oxygen to fuel ratio were varied to 
identify the effects on the syngas composition for downstream requirements for further processing.

\section{Simulation Basis}

Compositions of raw and lipid-extracted Nannochloropsisgaditana were used for thermodynamic modelling of algae gasification. The elemental compositions and higher heating values of raw algae (RA) and lipid-extracted algae (LEA), taken from the work of Barreiro et al [8], are shown in Table 1. The lipid content of the RA was $13.4 \%$, from which $11.1 \%$ mass was during extraction by $n$ hexane[8].

Table 1: Elemental composition, ash content and mineral elements in wt\% (dry basis), and heating value in $\mathrm{MJ} / \mathrm{kg}$ (dry basis) [8]

\begin{tabular}{ccc}
\hline Element & Raw algae & Lipid-extracted algae \\
\hline $\mathrm{C}$ & 47.6 & 43.9 \\
$\mathrm{H}$ & 7.5 & 7.1 \\
$\mathrm{~N}$ & 6.9 & 7.4 \\
$\mathrm{~S}$ & 0.5 & 1.1 \\
$\mathrm{O}$ & 25.1 & 26.0 \\
$\mathrm{Ash}$ & 12.4 & 14.5 \\
$\mathrm{Ca}$ & 0.50 & 0.62 \\
$\mathrm{Fe}$ & 0.62 & 0.05 \\
$\mathrm{~K}$ & 1.30 & 1.56 \\
$\mathrm{Mg}$ & 0.27 & 0.32 \\
$\mathrm{Na}$ & 3.02 & 3.64 \\
$\mathrm{P}$ & 1.43 & 1.72 \\
$\mathrm{Si}$ & $<0.003$ & $<0.003$ \\
$\mathrm{Zn}$ & 0.01 & 0.01 \\
$\mathrm{HHV}$ & 23.1 & 21.3 \\
\hline
\end{tabular}

Aspen Plus (Aspen Technology, Inc., Bedford, MA, USA) simulator was used thermodynamic equilibrium calculations. RA and LEA with $10 \%$ moisture content were used as the feedstock. Typical composition of oxygen stream (95\% oxygen, $3.4 \%$ argon and $1.6 \%$ nitrogen [13]) from an air separation unit (ASU) was used as the oxidant for the gasification. Redlich-Kwong-Soave equation of state with Boston-Mathias a function (RKS-BM) was used for property calculations for the gasification [14]. For solids (algae and ash) HCOALGEN and DCOALIGT models were used for enthalpy and density calculations [15].

A two-stage gasifier model, consisting of an RYIELD and an R-GIBBS reactor, was used for the calculation. The gasifier pressure was assumed to be 10 bar. Gasifier temperature was varied from 800 ${ }^{\circ} \mathrm{C}$ to $1400^{\circ} \mathrm{C}$, in order to cover the whole spectrum from fluidised-bed gasifier to entrained-flow gasifier. Heat loss from the gasifier was assumed to be $4 \%$ of the lower heating value (LHV) of the feedstock [16].

\section{Results and Discussion}

Gasification of RA and LEA were simulated using thermodynamic simulation. For thermodynamic calculations, the temperature of the gasifier is a function of fuel composition, fuel-to-oxidant ratio in the gasifier feed, and the loss of heat to the surroundings from the gasifier. The fuel-oxidant ratios were calculated to achieve gasifier temperatures between $800{ }^{\circ} \mathrm{C}$ and $1400{ }^{\circ} \mathrm{C}$ with a $50{ }^{\circ} \mathrm{C}$ interval. Fuel-oxidant equivalence ratios $(\varphi)$ for each temperature were calculated using the Eq.(1).

$$
\varphi=\frac{\text { FOR }}{(\text { FOR })_{\text {stoich }}}
$$

where, $\varphi$ is the fuel-oxidant equivalence ratio, FOR is the fuel-oxidant ratio on mass basis and $(F O R)_{\text {stoich }}$ is the fuel-oxidant ratio on mass basis for stoichiometric mixture.

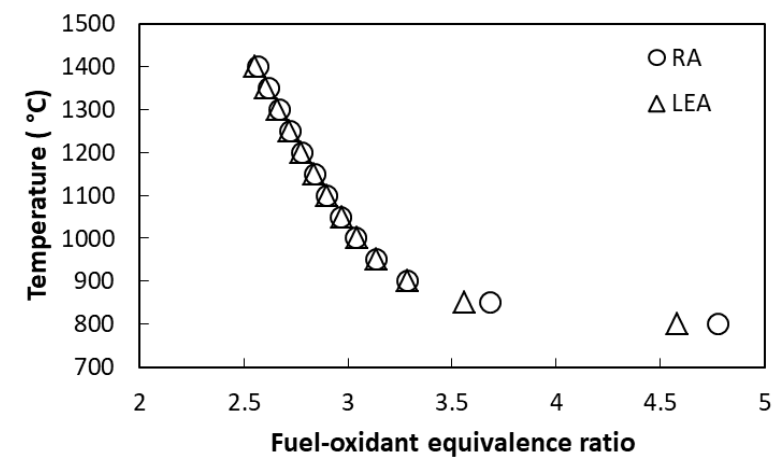

Fig.1: Gasification temperature versus equivalence ratio

The variation in the gasifier temperature as a function of the fuel-oxidant equivalence ratio is shown in Fig. 1. All $\varphi$ values are above 1, indicating fuel-rich conditions inside the gasifier. For $800{ }^{\circ} \mathrm{C}$ and $850{ }^{\circ} \mathrm{C}$, the simulation showed incomplete conversion of algal biomass to gas and ash. However, at temperatures above $900^{\circ} \mathrm{C}$, complete conversion could be achieved. Therefore, a small decrease in $\varphi$ (hence a small increase in oxidant) resulted noticeable increase in the gasifier temperature. Fig. 1 also shows that more oxidant was required for LEA to achieve the same temperature as RA gasification. This is due to the lower carbon and heat content of LEA than that of RA, caused by the extraction of lipid. As complete conversion of algae was not achieved at temperatures below $900{ }^{\circ} \mathrm{C}$, only temperatures between 900 and $1400{ }^{\circ} \mathrm{C}$ were considered in the following sections.

Gasification is a complex process of incomplete combustion of solid feedstock. Initially, algae undergo pyrolysis to produce volatiles and char. Volatiles reacts further with the oxygen and produce combustion products, i.e., $\mathrm{CO}_{2}, \mathrm{CO}, \mathrm{H}_{2} \mathrm{O}, \mathrm{H}_{2}, \mathrm{H}_{2} \mathrm{~S}$. Char also reacts with oxygen producing $\mathrm{CO}$ and $\mathrm{CO}_{2}$. In addition, char participates in steam and $\mathrm{CO}_{2}$ gasification (Boudouard reaction) and methanation reactions. There are also some gas-phase reactions 
of significant importance: water gas shift and steammethane reforming reactions.

The equilibrium compositions of syngas generated from RA at various temperatures are shown in Fig 2(a). The mole fraction of $\mathrm{CO}$ and $\mathrm{H}_{2} \mathrm{O}$ in the syngas increase as the gasifier temperature rises. Both the hydrogen and $\mathrm{CO}_{2}$ concentrations showed a decreasing trend with increasing temperature. Higher reaction temperatures favour both reverse water-gas shift and reverse Boudouard reactions, and therefore result an increase in the $\mathrm{CO}$ and $\mathrm{H}_{2} \mathrm{O}$ concentrations at the expense of hydrogen and $\mathrm{CO}_{2}$. Lower gasification temperatures showed presence of methane in the syngas. Methane mole fractions were 0.016 and 0.002 at 900 and $1000^{\circ} \mathrm{C}$, respectively. Above $1000{ }^{\circ} \mathrm{C}$, presence of methane in the syngas was insignificant. Lower temperatures and higher pressures favour the formation of methane. However, as the temperature increases, methane concentration diminishes due to consumption in combustion and steam-reforming reactions. The presence of methane in the syngas is desirable if the aim is to produce high-Btu syngas. On the other hand, if the syngas is produced as an intermediate feedstock for chemical production, methane will act as an inert. In such cases, methane formation should be minimized. Sulphur present in the algae found to be converted to $\mathrm{H}_{2} \mathrm{~S}$, the dominant sulphur containing species, the mole fraction of which remained almost constant for all temperatures. Trace amount of $\mathrm{SO}_{2}$ and $\mathrm{NH}_{3}$ formation was also found.

The compositions of syngas produced from LEA are shown in Fig. 2(b). The trends observed in the syngas composition with temperature variation are somehow similar. However, the syngas from LEA found to contain slightly lower $\mathrm{CO}$ mole fraction, due to the variation in elemental composition resulting from lipid extraction. Due to removal of some carbon and hydrogen, LEA had slightly lower LHV than RA (see Table 1). Also the ash content increased after lipid extraction. This required more energy to reach the same temperature as RA to heat up the excess ash as ballast in the gasifier at the expense of producing $\mathrm{CO}_{2}$ from $\mathrm{CO}$. In both Fig. 2(a) and 2(b), $\mathrm{YI}$ indicates the mole fraction of the inerts in the syngas, which is a combination of argon and nitrogen. These components were introduced to the system via the oxidant stream from ASU. The fuel nitrogen also contributed to some extent to the inert build-up in the syngas.

$\mathrm{H}_{2}$-to-CO ratio is an important parameter used for the evaluation of gasifier performance. The $\mathrm{H}_{2}$-to$\mathrm{CO}$ molar ratio as a function of temperature is shown in Fig. 3. $\mathrm{H}_{2}$-to- $\mathrm{CO}$ ratio for the RA syngas varied from 1.01 to 0.81 for $900{ }^{\circ} \mathrm{C}$ to $1400{ }^{\circ} \mathrm{C}$. For LEA, $\mathrm{H}_{2}$-to-CO ratio was slightly higher at $900^{\circ} \mathrm{C}$, 1.04 , than that of RA. LEA containing less carbon than the parent algae was the reason behind this variation. At $1400{ }^{\circ} \mathrm{C}$, the ratio for LEA was similar to that of RA. It must be noted that the syngas is rich in $\mathrm{CO}$, and hence water-gas shift is essential to increase the $\mathrm{H}_{2}$-to-CO ratio, if it is used for production of chemicals, such as methanol or dimethyl ether. If the syngas is used in a gas turbine, $\mathrm{H}_{2}$-to- $\mathrm{CO}$ ratio is of lesser importance. Both $\mathrm{H}_{2}$ and $\mathrm{CO}$ have similar HHV on volume basis. However, the $\mathrm{H}_{2}$-to-CO ratio of the syngas fed to the gas turbine can have an impact on the fugitive emissions from the gas turbine [17].

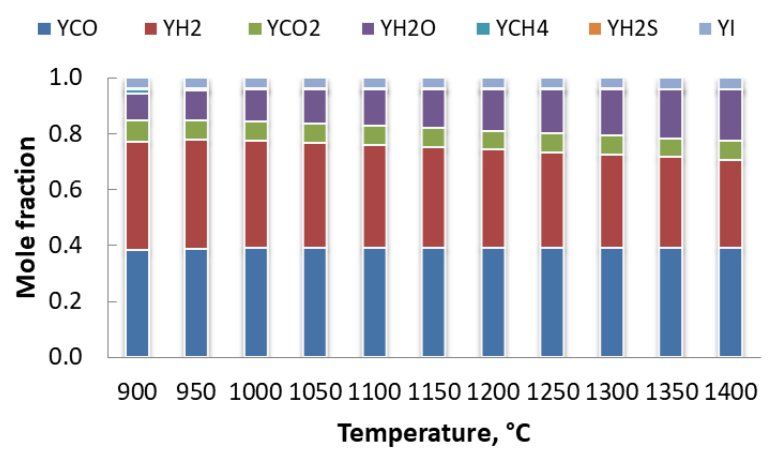

(a)

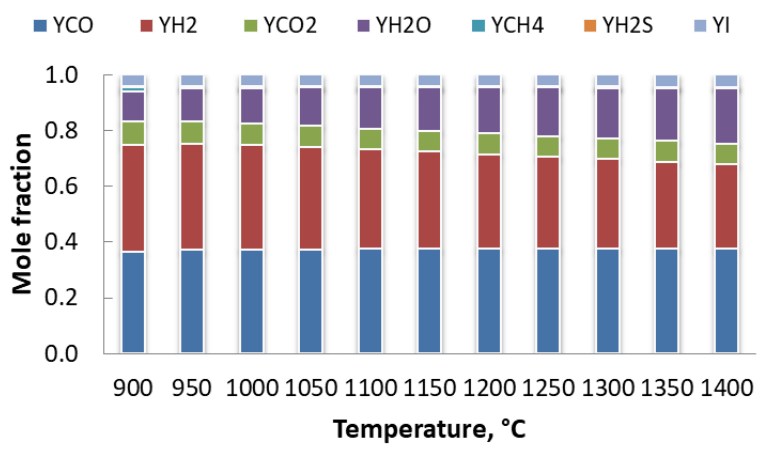

(b)

Fig.2: Syngas composition as a function of gasification temperature with feedstock (a) RA (b) LEA

The cold gas efficiency $\left(\eta_{\text {cold }}\right)$ is another important parameter used for evaluating the performance of the gasification process and is defined as shown in Eq. (2).

$$
\eta_{\text {cold }}=v_{g} Q_{g} / m_{a} Q_{a}
$$

where, $v_{g}$ is the volumetric flow rate of the syngas $\left(\mathrm{m}^{3} / \mathrm{s}\right), Q_{g}$ is the volumetric LHV of the syngas $\left(\mathrm{MJ} / \mathrm{m}^{3}\right), m_{a}$ is the mass flow rate of algae fed to the gasifier $(\mathrm{kg} / \mathrm{s})$ and $Q_{a}$ is the LHV of the algae $(\mathrm{MJ} / \mathrm{kg})$. LHV of the syngas was calculated using the mole fraction and LHV of individual components. LHV of the syngas from RA varied from 9.65 $\mathrm{MJ} / \mathrm{Nm}^{3}$ to $8.40 \mathrm{MJ} / \mathrm{Nm}^{3}$ for $900{ }^{\circ} \mathrm{C}$ to $1400{ }^{\circ} \mathrm{C}$ gasifier temperatures. For LEA syngas, LHV of the syngas were $9.33 \mathrm{MJ} / \mathrm{Nm}^{3}$ and $8.12 \mathrm{MJ} / \mathrm{Nm}^{3}$ at 900 ${ }^{\circ} \mathrm{C}$ and $1400{ }^{\circ} \mathrm{C}$, respectively. The heat content of the syngas decreased as the hydrogen content of the syngas decreased with increased temperature. The absence of methane in the higher temperature syngas also contributed to this reduction. 


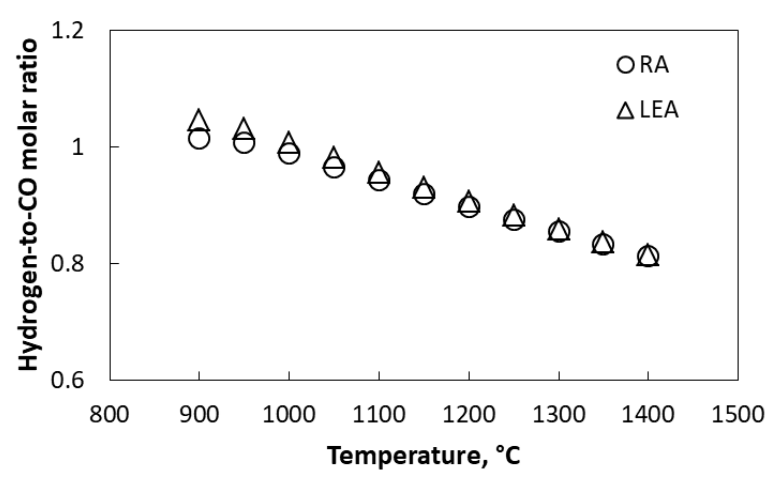

Fig.3: Hydrogen-to-CO molar ratio

$\eta_{\text {cold }}$ for RA and LEA syngas are shown in Fig. 4. There is a noticeable difference in the $\eta_{\text {cold }}$ for RA and LEA syngas. This is due to the lower carbon and hydrogen content in the LEA feedstock. $\eta_{\text {cold }}$ for RA and LEA syngas was $84 \%$ and $77 \%$, respectively, at a gasification temperature of 900 ${ }^{\circ} \mathrm{C}$. As the gasification temperature was increased to $1400{ }^{\circ} \mathrm{C}$, these values reduced to $75 \%$ and $69 \%$, respectively.

Gasification of RA would yield syngas only. On the other hand, RA to LEA to syngas pathway would have two products: lipid from extraction stage followed by syngas from the gasification of LEA. Carbon and hydrogen balance on the RA and LEA provides an approximate composition of the extracted lipid from Nannochloropsisgaditana. The heating value then can be calculated from correlations such as Boie's formula[8]. By performing carbon and hydrogen balance using the elemental composition of RA and LEA, and the amount of lipid extracted, it can be assumed that the lipid has an apparent formula of $\mathrm{C}_{6.4} \mathrm{H}_{10.7} \mathrm{O}_{0.75}$, with a calculated HHV of $38.3 \mathrm{MJ} / \mathrm{kg}$. To make a simple comparison between two pathways (RA to syngas, and RA to LEA and lipid followed by LEA to syngas), the heat content of the syngas from LEA times syngas yield were added to the heat content of the lipid times the lipid yield. This value was then compared with the heat content of syngas from RA multiplied by the syngas yield. It must be noted that none of the products are final products and require further processing to get a final product, such as biodiesel or methanol. However, this comparison will still provide a comparative idea on these two pathways. Considering same quantity of RA as the feedstock for both pathways, it was found that an energy penalty of $18 \%$ is realized if the LEA is gasified compared to the gasification of RA. However, LEA is a waste of the lipid-extraction process of biodiesel production from algal oil. Hence, gasification of LEA holds a prospect as a feedstock for gasification.

It should be mentioned here that the biochemical composition of algae varies from one species to the other to a great extent. The lipid content can vary from a few to more than $70 \%$ of the total mass.
However, the elemental composition of different species is not likely to vary much. With extraction of lipid the carbon and hydrogen contents are most likely to go down. Therefore, the observations made here are likely to hold for most algae species.

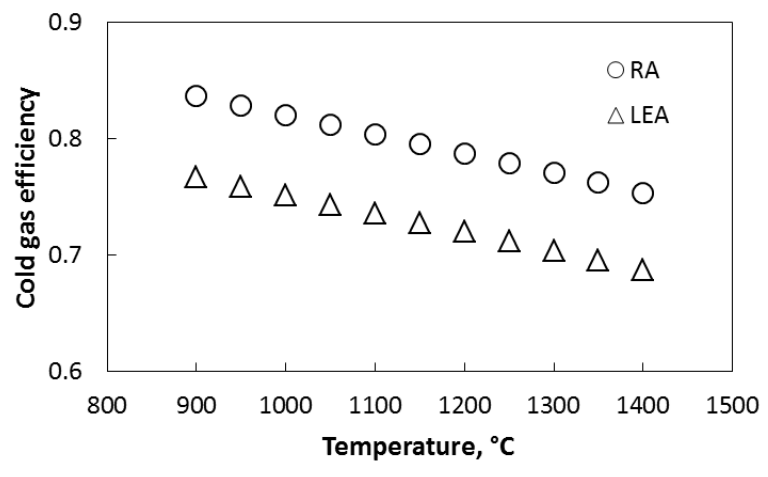

Fig.4:Cold gas efficiency of syngas

As the thermodynamic calculations are path independent, the calculations presented here are independent of the type of gasifier. However, this spectrum of temperature covers fluidised-bed gasifier at the lower end and entrained-flow gasifier at the higher end.

A comparison of the gasifier parameters are therefore presented in Table 2, to compare these two most like scenarios: fluidised-bed gasifier operating at $1000{ }^{\circ} \mathrm{C}$ and entrained-flow gasifier operating at $1400{ }^{\circ} \mathrm{C}$. As shown in Table 2, the gasifier running at $1000{ }^{\circ} \mathrm{C}$ for both RA and LEA has higher efficiency than the gasifier running at $1400{ }^{\circ} \mathrm{C}$. The $\mathrm{H}_{2}$-to-CO ratio at lower temperature gasifier is slightly favourable for chemical production from syngas.

Table 2: Performance of gasifiers at $1000{ }^{\circ} \mathrm{C}$ and $1400^{\circ} \mathrm{C}$

\begin{tabular}{|c|c|c|}
\hline Parameters & $\begin{array}{l}\text { Gasification } \\
\text { at } 1000^{\circ} \mathrm{C}\end{array}$ & $\begin{array}{l}\text { Gasification } \\
\text { at } 1400{ }^{\circ} \mathrm{C}\end{array}$ \\
\hline $\begin{array}{l}\mathrm{H}_{2} \text {-to-CO } \\
\text { molar ratio }\end{array}$ & $\begin{array}{l}0.99 \text { (RA); } \\
1.01 \text { (LEA) }\end{array}$ & 0.81 (RA and LEA) \\
\hline LHV & 9.2 (RA); & 8.40 (RA); \\
\hline$\left(\mathrm{MJ} / \mathrm{Nm}^{3}\right)$ & 8.9 (LEA) & 8.12 (LEA) \\
\hline $\begin{array}{l}\text { Cold gas } \\
\text { efficiency }\end{array}$ & $\begin{array}{l}0.82 \text { (RA); } \\
0.75 \text { (LEA) }\end{array}$ & $\begin{array}{l}0.75 \text { (RA); } \\
0.69 \text { (LEA) }\end{array}$ \\
\hline
\end{tabular}

However, downstream water-gas shift reactors are required to shift the ratio to the desired level. The thermodynamic calculations, therefore, suggest that the gasification of algae, whether raw or lipidextracted, may be operated at lower temperatures in fluidised-bed or, in a catalytic entrained flow reactor. It must be kept in mind that the thermodynamic calculations calculate the equilibrium compositions only and might not be able to predict the formation and retention of tar products at fluidised-bed conditions. The algae under consideration contains high amount of $\mathrm{Na}$ and $\mathrm{K}$ with low amount of $\mathrm{Ca}$ in ash (see Table 1). This quantity becomes even higher after lipid extraction. It is to be noted that the Si content is very low for both before RA and LEA. 
Si inhibits the catalytic activity if its quantity is higher than the combined amount of $\mathrm{Na}$ and $\mathrm{K}[11,18,19]$ as they might take part in forming silicates. For the current species under study, the Si content was significantly lower than $\mathrm{Na}$ and $\mathrm{K}$, making it highly suitable for catalytic gasification. Recent studies on alkali catalyzed gasification showed that as the total alkali $(\mathrm{Na}+\mathrm{K})$ to carbon ratio in char increases, the reactivity increases drastically during low temperature gasification $\left(<850{ }^{\circ} \mathrm{C}\right)$ [20]. On the other hand, at higher temperatures, part of the alkali is evaporated to exert other activities such as tar destruction and soot reduction [21,22]. In all scenarios, the lipid extracted algae species (Nannochloropsisgaditana) stands out as a suitable candidate for catalytic gasification. However, as the assessment of the catalytic activity is beyond the scope of this study, this is a topic for future research.

\section{Conclusion}

Gasification of Nannochloropsis gaditana, before lipid extraction (RA) and after lipid extraction (LEA), between 800 and $1400{ }^{\circ} \mathrm{C}$ was simulated using thermodynamic model in Aspen Plus. Tempertures above $900{ }^{\circ} \mathrm{C}$ were able to convert algae completely to syngas and residual ash. The RA syngas found to have slightly more $\mathrm{CO}$ than that of LEA syngas. The $\mathrm{H}_{2}$-to-CO ratios for both syngases had almost identical values. However, the RA syngas found to have higher heat content and cold gas efficiency than LEA syngas. Simple energy balance on the RA to syngas and RA to LEA to syngas pathways indicate that there is a $18 \%$ energy penalty for the RA to LEA to syngas pathway. However, LEA is a waste of the lipid extraction stage with moderate carbon content. A suitable method of extraction of energy from LEA is therefore essential make the lipid extraction process more desireable. The simulation results indicates that LEA is almost as suitable as the RA as a gasifier feedstock. Gasification at lower temperature assuming catalytic effect from the alkali metals present in the LEA ash can make its gasification an attractive process for energy conversion.

\section{References}

1. Monroe R. Around the Pier: Record Annual Increase of Carbon Dioxide Observed for 20152015.

2. Jacob DJ, Winner DA. Effect of climate change on air quality. Atmos Environ J 2009;43:51-63.

3. U.S. Faces Dramatic Rise in Extreme Heat, Humidity. Clim Cent 2016.

4. Demirbas A. Use of algae as biofuel sources. Energy Convers Manag 2010;51:2738-49.

5. Demirbas A, Fatih Demirbas M. Importance of algae oil as a source of biodiesel. Energy Convers Manag 2011;52:163-70.

6. Malcata FX. Microalgae and biofuels: A promising partnership? Trends Biotechnol 2011;29:542-9.
7. Kassim MA, Kirtania K, De La Cruz D, Cura N, Srivatsa SC, Bhattacharya S. Thermogravimetric analysis and kinetic characterization of lipid-extracted Tetraselmis suecica and Chlorella sp. Algal Res 2014;6:39-45.

8. López Barreiro D, Samorì C, Terranella G, Hornung $U$, Kruse A, Prins W. Assessing microalgae biorefinery routes for the production of biofuels via hydrothermal liquefaction. Bioresour Technol 2014;174:256-265.

9. Kirtania K, Joshua J, Kassim MA, Bhattacharya S. Comparison of $\mathrm{CO} 2$ and steam gasification reactivity of algal and woody biomass chars. Fuel Process Technol 2013:0-8.

10. Kirtania K, Bhattacharya S. Pyrolysis kinetics and reactivity of algae-coal blends. Biomass and Bioenergy 2013; 55:291-8.

11. Kirtania K, Bhattacharya S. $\mathrm{CO}_{2}$ Gasification Kinetics of Algal and Woody Char Procured under Different Pyrolysis Conditions and Heating Rates. ACS Sustain Chem Eng 2015;3:365-73.

12. Elliott DC, Hart TR, Schmidt AJ, Neuenschwander GG, Rotness LJ, Olarte M V., et al. Process development for hydrothermal liquefaction of algae feedstocks in a continuous-flow reactor. Algal Res 2013;2:445-54.

13. Bell DA, Towler BF. Coal gasification and its applications. William Andrew; 2010.

14. Finlayson BA. Introduction to Chemical Engineering Computing. Wiley; 2012.

15. ASPENTech. Aspen physical property system: physical property models. Burlington: Aspen Technology, Inc; 2013.

16. Andersson J, Umeki K, Furusjö E, Kirtania K, Weiland F. Multiscale Reactor Network Simulation of an Entrained Flow Biomass Gasifier: Model Description and Validation. Energy Technol 2017;5:1484-94.

17. Lee MC, Seo S Bin, Chung JH, Kim SM, Joo YJ,Ahn $\mathrm{DH}$. Gas turbine combustion performance test of hydrogen and carbon monoxide synthetic gas. Fuel 2010;89:1485-1491.

18. Yuan S, Chen X, Li J, Wang F. CO2 Gasification Kinetics of Biomass Char Derived from HighTemperature Rapid Pyrolysis. Energy \& Fuels 2011;25:2314-21.

19. Zhang Y, Ashizawa M, Kajitani S, Miura K. Proposal of a semi-empirical kinetic model to reconcile with gasification reactivity profiles of biomass chars. Fuel 2008;87:475-81.

20. Kirtania K, Axelsson J, Matsakas L, Christakopoulos $P$, Umeki K, Furusjö E. Kinetic study of catalytic gasification of wood char impregnated with different alkali salts. Energy 2016;118:1055-65.

21. Umeki K, Häggström G, Bach-oller A, Kirtania K, Furusjö E. Reduction of Tar and Soot Formation from Entrained Flow Gasification of Woody Biomass by Alkali Impregnation. Energy \& Fuels 2017.

22. Bach-oller A, Kirtania K, Furusjö E, Umeki K. Cogasification of black liquor and pyrolysis oil at high temperature: Part 1 . Fate of alkali elements. Fuel 2017;202:46-55. 